\title{
EDITORIAL
}

\section{LEITURAS E AÇÕES NA ENCONTROS BIBLI}

\author{
URSULA BLATTMANN
}

Em cada edição publicada merece o destaque a participação de autores, avaliadores e demais colegas. É um momento que deve ser festejado, pois são etapas nas quais a perseverança, a vontade de fazer e a pontualidade estão presentes.

Das leituras dos originais à tomada de decisão pelo aceite ou não, se efetua por tantas mãos e se torna uma rotina, por vezes grata, outras, ingrata. Os afazeres e ações na nossa rotina interna da Encontros Bibli provém desta força maior que nos anima a cada edição publicada. E compartilhamos a todos os leitores a satisfação de apresentar a edição do volume 15, número 29 com 10 (dez) artigos e um dossiê referente ao Encontro sobre Repositórios de Objetos Virtuais, realizado em novembro de $2009 \mathrm{em}$ Florianópolis.

Os artigos são de 17 colegas que atuam em sete universidades, sendo cinco brasileiras; uma argentina; uma espanhola; do Instituto Federal de Educação, Ciência e Tecnologia de Paraíba e do Instituto Brasileiro de Informação, Ciência e Tecnologia. Expressamos nossa admiração aos pesquisadores que se dedicam ao ensino e a pesquisa de nossa área do conhecimento e conseguem criar espaços para escrever e publicar, contribuindo com suas reflexões e análises para o crescimento da Ciência da Informação.

Os textos tramitaram nos fluxos do processo editorial desde o início de 2009 e agora tornam-se disponíveis aos leitores:

O campo da ciência da informação e o patrimônio cultural: reflexões iniciais para novas discussões sobre os limites da área, de Willian Eduardo Righini de Souza e Giulia Crippa.

A infra-estrutura em informação científica e em Ciência da Informação na antiga União Soviética (1917-1991), escrita por Roberto Lopes dos Santos Júnior e Lena Vânia Ribeiro Pinheiro.

O profissional bibliotecário como gestor de pessoas, na visão de Adilson Luiz Pinto e de José Antonio Moreiro González.

Fluxos informacionais para o monitoramento da Convenção dos Direitos da Criança: a atuação da rede $N G O$ Group for $C R C$, de Maria Guiomar da Cunha Frota e Paula Gomes Quintão.

Produção científica dos pesquisadores brasileiros que depositaram patentes na área da biotecnologia, no período de 2001 a 2005: colaboração interinstitucional e interpessoal, de Ana Maria Mielniczuk de Moura e Sônia Elisa Caregnato.

Utilizando a análise de citações de teses para avaliar a coleção de livros em bibliotecas universitárias; de Ana Maria Mattos e Tânia Marisa de Abreu Fraga.

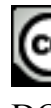
DOI 10.5007/1518-2924.2010v15n29pi

Enc. Bibli: R. Eletr. Bibliotecon. Ci. Inf., ISSN 1518-2924, Florianópolis, v.15, n. 29, p.i-ii, 2010. 
Medición de la capacidad docente de la colección de una biblioteca universitária, da Maria Teresa Costamagna.

Scripts de atendimento em call centers: uma visão de documentos eletrônicos, de Sandra Maria Silveira e Maria Aparecida Moura.

Busca de informações pelos alunos dos cursos superiores do Centro Federal de Educação Tecnológica da Paraíba, por Beatriz Alves de Sousa e Valmira Perucchi.

Perspectivas de letramento informacional no Brasil: práticas educativas de bibliotecários em escolas de ensino básico, de Bernadete Santos Campello.

No dossiê, estão resgatadas as discussões realizadas em novembro de 2009 sobre Repositórios Institucionais e Objetos Virtuais de Aprendizagem, em evento realizado na Universidade Federal de Santa Catarina (campus Florianópolis). Cumpre destacar a abrangência dos temas e a atualidade das apresentações efetuadas por dezesseis especialistas, que trouxeram discussões com um grau de liberdade que se mostra especialmente pertinente em novas áreas de estudo e atuação.

Cabe destacar as mudanças que acontecem na Universidade Federal de Santa Catarina com a expansão do ensino pelo interior do estado, isto é, abertura de cursos presenciais de ensino superior nas cidades de Joinville, Araranguá e Curitibanos. Em Florianópolis a UFSC expandiu a oferta de cursos, dentre os quais está a criação do Curso de Graduação em Arquivologia, proposto pelo Departamento de Ciência da Informação da Universidade Federal de Santa Catarina, que iniciou sua primeira turma em março de 2010. Com as perspectivas de reflexões para publicações sobre ensino, pesquisa e extensão na área de Arquivologia, a Encontros Bibli pretende expandir a discussão sobre o tema e para isso reitera o convite aos autores que tratam desta temática para encaminharem seus textos no nosso processo de editoração.

Entendemos que a comunicação científica é o coração da ciência e aproveitamos esse momento para agradecer a todos os autores, avaliadores, editores, bolsistas, leitores e demais colaboradores que fazem da Encontros Bibli um canal de informação relevante na Ciência da Informação, Biblioteconomia e Arquivologia.

A presente edição teve como parceiras de editoria as colegas de jornadas: as professoras Rosângela Schwarz Rodrigues ( rosangela@cin.ufsc.br ) e Araci Isaltina Andrade Hillesheim ( araci@,cin.ufsc.br ). Desejamos uma boa leitura e aguardamos sua colaboração para uma próxima jornada.

Florianópolis, Ilha de Santa Catarina, maio de 2010.

Ursula Blattmann

Editora

Enc. Bibli: R. Eletr. Bibliotecon. Ci. Inf., ISSN 1518-2924, Florianópolis, v.15, n. 29, p.i-ii, 2010. 